\title{
Problemas do discurso de Deepak Chopra: uma análise metalinguística de
} "A cura quântica""

\author{
Daniel Pigozzo ${ }^{1}$ \\ Matheus Monteiro Nascimento ${ }^{1}$ \\ Nathan Willig Lima ${ }^{1}$ \\ Instituto de Física - Universidade Federal do Rio Grande do Sul
}

\section{Resumo}

Neste artigo, nosso objetivo é contribuir para o debate sobre o misticismo quântico, explorando aspectos discursivos que permeiam um enunciado com tal tema. Para tanto, realizamos uma análise metalinguística do livro A cura quântica de Deepak Chopra, com base na filosofia da linguagem do Círculo de Bakhtin. Investigamos não apenas as estratégias argumentativas do autor, mas também conectamos os elementos constitutivos desse enunciado (tema, estrutura e estilo) com seu contexto de produção e publicação. A partir da análise reconhecemos a incoerência de Chopra ao sintetizar visões de mundo místicas e alternativas e uma visão de mundo científica repleta de metáforas inconsistentes e graves contradições, mas destacando como o autor conseguiu influenciar o modo como conceitos relacionados à Física Quântica são mobilizados fora do contexto acadêmico.

Palavras-chave: Misticismo Quântico; Física Quântica; Metalinguística; Bakhtin.

\begin{abstract}
In this article, our objective is to make some contributions to the debate around the "quantum mysticism" phenomenon, exploring discursive aspects that permeate an utterance with this kind of theme. To this end, we bring forth an analysis of the book Quantum healing by Deepak

\footnotetext{
+ Problems of Deepak Chopra's discourse: a metalinguistic analysis of "Quantum healing”

* Recebido: 31 de agosto de 2020. Aceito: 19 de abril de 2021.

${ }^{1}$ E-mails: danielpigozzo95@gmail.com; matheus.monteiro@ufrgs.br; nathan.lima@ufrgs.br
} 
Chopra, based on the philosophy of the Bakhtin Circle. We investigate not only the author's argumentative strategies, but we also connect the constituent elements of this utterance (theme, structure and style) with its context of publication, production and reception. We end our arguments recognizing the incoherence that Chopra demonstrates with his intertwining of mystical and alternative conceptions with a scientific worldview, while uttering inconsistent metaphors and serious contradictions, but we also highlight that the author was able to influence the way in which concepts related to Quantum Physics circulate outside the academia.

Keywords: Quantum Mysticism; Quantum Physics; Metalinguistics, Bakhtin.

\section{Introdução}

O interesse por Física Quântica (FQ) e seus entrelaçamentos com assuntos como misticismo, "filosofias orientais" e medicina alternativa têm sido pautado por diversos trabalhos de pesquisa acadêmica; muitos deles devotados à análise histórica e epistemológica desse fenômeno que pode ser denominado "fenômeno cultural do misticismo quântico" (PAURA, 2018; PESSOA JR., 2011; SAITO, 2019). No Caderno Brasileiro de Ensino de Física, a título de exemplo, foram publicados dois trabalhos recentes que investigam aspectos relacionados ao fenômeno de diferentes maneiras; trabalhos a cujas discussões pretendemos dar continuidade (MOURA; SANTOS, 2017; PIGOZZO; LIMA; NASCIMENTO, 2019).

Para ilustrar o alcance desse "fenômeno cultural", basta colocar no buscador do Google termos como cura quântica e saúde quântica para observar que o número de resultados é relativamente semelhante ao apresentado quando a busca é pelos termos mecânica quântica e física quântica ${ }^{2}$. Em buscas com os mesmos termos em inglês, os resultados também são notáveis ${ }^{3}$. Portanto, é razoável afirmar que a quantidade de páginas que tratam de temas relacionados a concepções místicas ${ }^{4}$ sobre conceitos de Física Moderna e Contemporânea (FMC) é praticamente da mesma ordem de grandeza do número de páginas que trazem o termo Física Quântica.

\footnotetext{
2 Aproximadamente, 1.140.000 resultados para cura quântica, 3.190.000 resultados para saúde quântica, 1.240.000 resultados para mecânica quântica e 3.230.000 resultados para física quântica. Acesso em 20 de maio de 2020 .

3 Aproximadamente, 23.000.000 resultados para quantum healing, 261.000.000 resultados para quantum health, 150.000 .000 resultados para quantum mechanics e 219.000.000 resultados para quantum physics. Acesso em 20 de maio de 2020 .

4 O tema também é amplamente associado, em artigos e textos acadêmicos, a termos como pseudociência, charlatanismo, esoterismo, oportunismo, negacionismo (histórico e científico), entre outros.
} 
Na Educação em Ciências, o tema já foi associado ao desenvolvimento de concepções alternativas e entendimentos equivocados sobre FQ, mas que são amplamente compartilhados entre diversos grupos sociais. Dificuldades e incompreensões que causam grandes afastamentos entre como a FQ é compreendida pela sociedade em geral e como ela fundamenta diversos consensos científicos contemporâneos são frequentemente destacados como parte de um conjunto de obstáculos a serem superados no processo de ensinoaprendizagem de FMC nos mais diversos espaços educacionais (CUESTA-BELTRÁN, 2018; GRECA; FREIRE, 2014; HILGER; MOREIRA, 2012; HILGER; MOREIRA; DA SILVEIRA, 2009; PEREIRA; OSTERMANN, 2009).

Associações semelhantes também são frequentemente feitas em relação a indivíduos como Deepak Chopra, criador do conceito de "cura quântica" e ao fenômeno cultural que ele representa. Na mídia tradicional e na independente, textos que tratam sobre as obras, os eventos e a vida de Chopra são escritos tanto de formas relativamente simplistas e ingenuamente favoráveis ao tema, quanto de formas agressivas e depreciativas (ALMEIDA, 1999; INDIATODAY.IN, 2015; LANG, 2000; PLAIT, 2009). No contexto da produção acadêmica especializada, as abordagens dos trabalhos que tratam sobre o tema também são consideravelmente diversas, mas frequentemente mais analíticas, ponderadas e aprofundadas (BAER, 2003; MOURA; SANTOS, 2017; PESSOA JR., 2011; WARRIER, 2019).

As reações à obra de Chopra se popularizaram a partir dos anos de 1990, na época de publicação do livro "Ageless body, timeless mind: the quantum alternative to growing old" (1993), quando ele participou do programa de televisão de Oprah Winfrey; acontecimento que o inseriu definitivamente no imaginário popular. Segundo Paul A. Offit (2013), 137 mil cópias do livro foram vendidas nas 24 horas seguintes. Desde então, críticos a Chopra e à sua obra questionam a responsabilidade de seus atos e acusam-no de mentiras e oportunismo (PLAIT, 2009; WHEEN, 2004). Apesar do enriquecimento "acelerado" em diferentes períodos, os atos polêmicos de Chopra nunca envolveram um caso de justiça fundamentado em irregularidades financeiras sistêmicas ou enriquecimento ilícito, mas já envolveram a omissão de interesses financeiros na publicação de um artigo em um periódico científico renomado, o estabelecimento de atendimentos particulares sem licença médica e, além disso, práticas hostis em ações judiciais contra jornais, revistas, periódicos e tabloides (NY TIMES, 1996).

Independentemente das ações praticadas por Chopra e de outros representantes deste movimento que ainda cresce por todo o mundo (DOERING-MANTEUFFEL, 2011), neste trabalho estamos especialmente interessados em entender a natureza do enunciado de Chopra e os elementos constitutivos de seu discurso. Isto é, reconhecendo que muitas pessoas são introduzidas a uma suposta visão de Física Quântica através dos livros do Deepak Chopra e de ideias que ele ajudou a criar ou disseminar, é importante investigar profundamente esse enunciado, explicitando suas características composicionais e estilísticas, seus compromissos teóricos e filosóficos, a que outros enunciados ele responde, como ele se relaciona com os 
enunciados seminais da Física, que novos enunciados ele suscita, e como ele se relaciona de uma forma mais geral, com a sociedade e com a cultura. Defendemos que tal investigação nos dará subsídios para entender melhor o fenômeno cultural do misticismo quântico, a difusão de seus conceitos na sociedade, bem como refletir sobre como o ensino formal de ciências pode se organizar para debater explicitamente os problemas levantados por tal literatura.

Analisar como Chopra interpreta (e discursa sobre) Física Quântica gera diversos desdobramentos específicos para a Educação em Ciências. Isto porque, se temos como objetivo a superação de quaisquer tipos de "concepções alternativas" ou incompreensões referentes à FQ que estudantes e até mesmo docentes possam apresentar ao se comunicarem em salas de aula (ao ponto de ser comum associarem FQ a produtos como "colchões magnéticos", a práticas como "massagens quânticas" ou exclusivamente a assuntos como "alma" e "espiritualidade") é necessário que saibamos as origens desses potenciais obstáculos pedagógicos e quais conceitos eles mobilizam. A cura quântica é um dos principais pontos de origem dessas ideias ou, no mínimo, está fortemente relacionada a elas.

Considerando isso, apresentamos uma análise metalinguística (presente na seção IV), fundamentada na filosofia da linguagem do Círculo de Bakhtin ${ }^{5}$ (abordada na seção III) do livro A cura quântica, uma das principais materializações do fenômeno cultural do misticismo quântico, escrito por Deepak Chopra (sobre quem apresentamos mais informações especificamente na subseção IV.1.2). Para tanto, nossas questões de pesquisa são as seguintes: Qual é o tema do enunciado de Chopra? A que gênero do discurso ele pertence? Em qual contexto extraverbal ele é estruturado? Qual sua estrutura composicional e estilo? A quem o enunciado é direcionado e a quem ele responde? Como esses elementos sustentam o projeto de fala do autor?

Na próxima seção, contudo, antes de partirmos para o quadro teórico-metodológico e para os resultados da investigação, justificamos a realização da presente pesquisa a partir de um levantamento da percepção dos usuários da rede social Twitter sobre o termo Física Quântica que será capaz de dar uma boa noção da disseminação deste fenômeno.

\section{A Física Quântica no Twitter}

A análise de postagens em redes sociais insere-se no campo de estudo da mineração de textos, ramo crescente da estatística nos últimos anos (SILGE; ROBINSON, 2017). A ideia principal é selecionar um número expressivo de postagens sobre temas ou usuários específicos e realizar análises diversas, como recorrência de palavras, análise de sentimento e associação de termos. Para os objetivos deste trabalho, analisamos apenas a recorrência de palavras em postagens sobre Física Quântica a fim de mapear qual o entendimento de parte da população sobre esta área da Física. Para efeito de comparação, também analisamos postagens

\footnotetext{
${ }^{5}$ Grupo de filósofos formado por Mikhail Bakhtin, Valentin Volóchinov e Pável Medviédev.
} 
que continham apenas o termo Física. O ambiente de programação $\mathrm{R}$ foi utilizado na busca das postagens e nas análises estatísticas (R CORE TEAM, 2015).

A seleção de postagens foi feita em 28 de junho de 2020. Nesta data, foram buscados os últimos 500 tweets que continham os termos \#physics e \#quantumphysics. A busca foi realizada nos termos em inglês para contemplar um grupo mais heterogêneo de usuários. Em cada conjunto de postagens analisamos as vinte palavras mais frequentes. As Fig. 1 e 2 mostram as palavras mais frequentes em 500 tweets que continham os termos já mencionados.

Olhando para as palavras mais frequentes nos tweets que contêm o termo physics, notamos que não há a presença de termos relacionados com misticismos ou elementos do movimento Nova Era. As palavras mais associadas com physics são usualmente proferidas em ambientes educacionais e acadêmicos, como escolas e universidades. Alguns termos podem causar estranhamento, como pay (pagamento, remuneração, salário) ou finance (finança, financiar, custear). A análise mais detalhada destas postagens mostra que estas palavras estão relacionadas com cursos de Física vendidos na internet e divulgados pelo Twitter. De qualquer forma, fica evidente que esta parte da população analisada não associa o termo physics com elementos do misticismo.

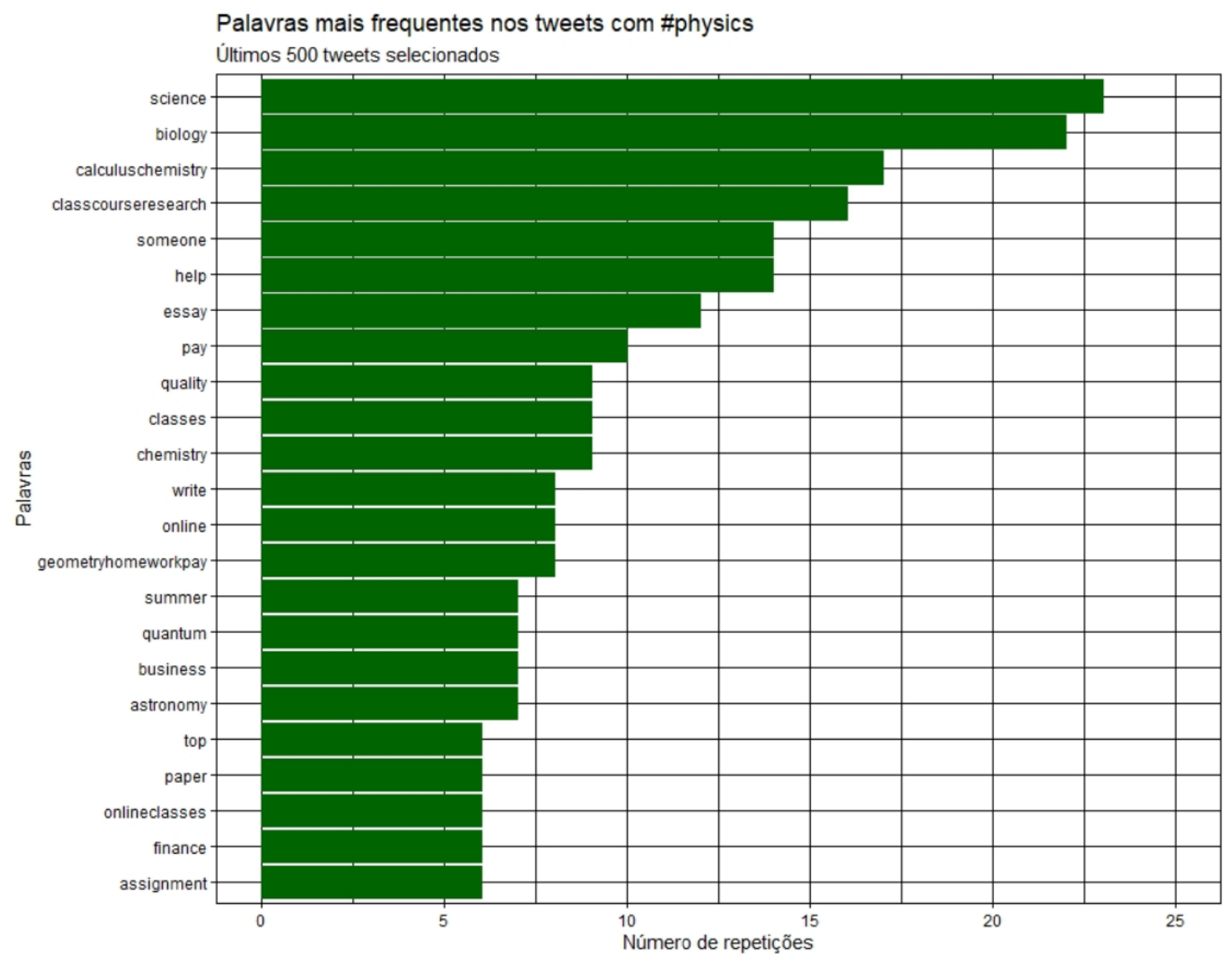

Fig. 1 - Palavras mais frequentes nos tweets com o termo physics. 


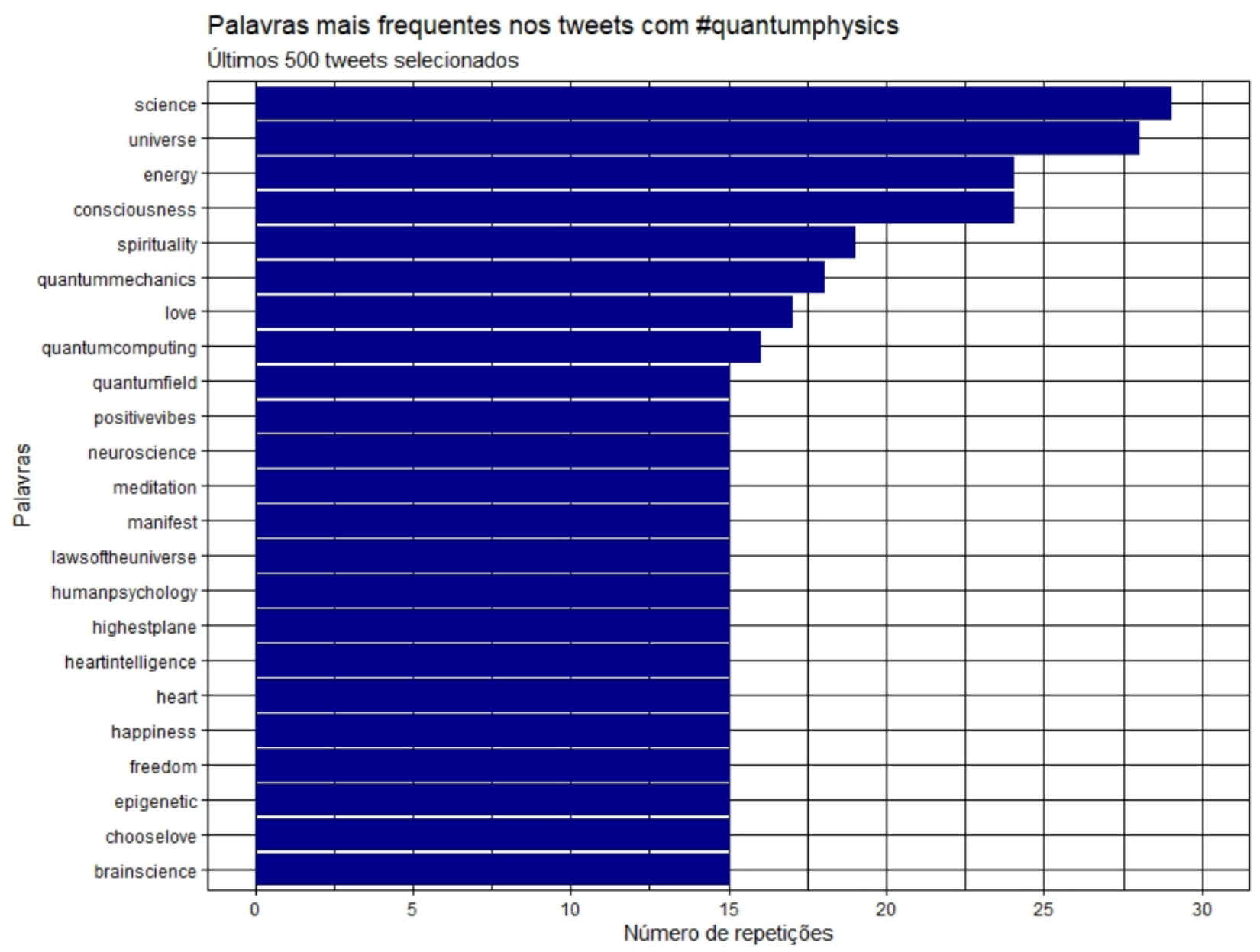

Fig. 2 - Palavras mais frequentes nos tweets com o termo quantum physics.

Já com as palavras mais frequentes nos tweets que contêm o termo quantum physics observamos um cenário completamente diferente. Fica claro que esta parte da população aparentemente possui um entendimento muito difuso do que é Física Quântica. A presença de palavras como consciousness (consciência), spirituality (espiritualidade), love (amor) e meditation (meditação), por exemplo, revela a forte influência que autores como Chopra tiveram na divulgação da Física Quântica para as pessoas. Mas por que as pessoas não possuem este mesmo entendimento quando falamos da Física em geral? Como a Física Quântica é difundida nestas obras e é capaz de produzir tal entendimento? Nosso trabalho pretende apresentar algumas respostas para estas questões a partir da análise aprofundada da obra "Cura Quântica" de Chopra. Na próxima seção apresentamos o quadro teóricometodológico utilizado na análise desta obra.

\section{Quadro teórico-metodológico}

Nessa seção, buscamos apresentar brevemente a Teoria do Enunciado Concreto (TEC) e a Interpretação Metalinguística (IM) do Círculo de Bakhtin; grupo de filósofos ao qual iremos nos referir apenas como "o Círculo". Para isso, orientamos a discussão 
destacando conceitos-chave tais como ato, enunciado e gênero do discurso a partir das obras do Círculo (BAKHTIN, 2002, 2010, 2011; MEDVIÉDEV, 2012; VOLÓCHINOV, 1981, 2018) e de diversos outros trabalhos (LIMA et al., 2019; MACHADO, 2005; SOUZA, 2002; VENEU; FERRAZ; REZENDE, 2015).

A IM é o paradigma, a prática ou a disciplina de análises que busca estudar o enunciado concreto, correlacionar materiais linguísticos concretos e, baseada na aplicação de um método sociológico ao estudo da linguagem, explicitar conflitos e correlações entre enunciados e teorias. Com ela, é possível realizar estudos do discurso que buscam complementar e até mesmo ultrapassar, legitimamente, os limites da linguística, mas sem ignorá-la, ou seja, ainda considerando suas possíveis análises e resultados. A TEC, por sua vez, pode ser entendida como a arquitetônica conceitual da análise da linguagem através da unidade concreta da comunicação discursiva ou, ainda, como a base, estabelecida em textos como Os gêneros do discurso (BAKHTIN, 2011), da análise da natureza dos enunciados e da diversidade de gêneros do discurso nos diversos campos da atividade humana; uma análise em que há uma síntese dialética contrária aos pressupostos do subjetivismo idealista e do objetivismo abstrato que pode ser entendida em parte como reflexo da visão éticofenomenológica de Bakhtin (LIMA et al., 2019; SOUZA, 2002).

Passando para a definição dos conceitos, começamos pelo enunciado que é, como posto pelo Círculo, a "unidade da comunicação discursiva". Todo enunciado possui como características principais a troca comunicativa entre sujeitos do discurso (entre falante e ouvinte, entre locutor e interlocutor), a alternância entre tais sujeitos (elemento que delimita o enunciado) e o pertencimento a um gênero do discurso (forma relativamente estável de comunicação verbal). Outras características importantes são as seguintes: o pertencimento a uma cadeia de outros enunciados (passados e futuros) e a presença de totalidade semântica (tema, estilo e estrutura composicional).

Todo enunciado é um ato de comunicação discursiva, sendo o ato a unidade integral e singular de ocorrência única determinada por uma orientação social e detentora de uma dimensão ética e uma dimensão fenomenológica. Entre essas características, a alternância entre sujeitos do discurso é a principal, pois, de certa forma, abarca todas as outras e pode ser entendida pela convergência de três fatores: a exauribilidade semântica-objetal de um tema (quantidade de elaboração e esforço adequados ao enunciar-se sobre determinado assunto), o projeto de fala (intencionalidades de um enunciado que um interlocutor ou auditório identifica ou reconhece) e, por fim, o gênero do discurso (forma composicional arquetípica de construção de enunciados).

$\mathrm{O}$ ato discursivo representado pela comunicação através de um enunciado em forma de livro é dialógico e cabe ser analisado através da TEC e da IM porque, segundo o Círculo, toda comunicação discursiva é composta por sujeitos ativos e responsáveis; dessa forma, mesmo a compreensão de um leitor sobre um livro é um ato ativo. Além disso, o enunciado não é um ato individual que só pode ser explicado por processos mentais do sujeito do 
discurso. $\mathrm{O}$ enunciado, como o ato, possui dupla responsabilidade: responde pelo mundo da vida (o mundo do Ser, o mundo da subjetividade) e pelo mundo da cultura, ou seja, o enunciado é dialógico, interdependente e não expressa apenas características subjetivas, mas expressa (e é moldado por) aspectos sociais. O enunciado é criado na articulação entre o campo da atividade humana em que se insere e o campo da expressão subjetiva do indivíduo.

Dessa forma, não há nenhum sujeito com uma posição privilegiada para criar ou analisar um enunciado, mesmo que o enunciado seja sobre o próprio sujeito, pois não há nenhum juízo, argumento ou texto capaz de evidenciar ou descrever a experiência do Ser ou a realidade material de forma absoluta, objetiva e verdadeira. Isto é, não há um enunciado que não herde as visões de mundo ou as vozes de outros enunciados e locutores e que não seja orientado a um interlocutor que, ao compreendê-lo e respondê-lo, realiza um ato e cria um elo na cadeia de enunciados da comunicação discursiva.

A compreensão e a responsibilidade (o ato de responder ou referenciar) de um enunciado concreto estão fortemente relacionadas a qual gênero do discurso ele pertence, ou seja, a qual categoria relativamente estável, bem estabelecida, de enunciados ele pertence. A identificação do gênero discursivo pela análise metalinguística contribui para a determinação da finalidade de um enunciado concreto e do campo da atividade humana no qual ele se insere.

Para finalizar, gostaríamos de enfatizar a importância dos gêneros do discurso para a filosofia do Círculo já que eles são, como comentado anteriormente, parte do conjunto de fatores que delimitam os enunciados e que caracterizam a alternância de sujeitos do discurso. Todo enunciado deve inexoravelmente pertencer a um gênero do discurso, por ser sempre necessário o reconhecimento de normas e contextos quando enunciamos algo e ao sermos respondidos por isso, essas formas estáveis de enunciados acabam por variavelmente "restringir" a liberdade do sujeito do discurso de se comunicar e, de certa forma, impossibilitando que atos de comunicação sejam completamente subjetivos no sentido de representarem exatamente os processos mentais de um indivíduo.

\section{Análise metalinguística de A cura quântica}

Seguimos, nesta seção, a trajetória analítica de interpretação de enunciados concretos delineada no trabalho de Lima et al. (2019). A primeira etapa consiste em delimitar o enunciado e seu contexto imediato, identificando a alternância de sujeitos, o conteúdo temático e informações sobre o autor (de onde e quando se enuncia). A segunda etapa serve para identificar o gênero discursivo do enunciado, procurando destacar as finalidades e as condições do tipo de atividade humana em que esse enunciado se insere. Na terceira etapa, buscamos analisar o direcionamento e a orientação social do enunciado, tentando compreender a quem ele é destinado.

Posteriormente, na quarta etapa, focamos na responsividade do enunciado, ou seja, a quem e a que outros discursos o enunciado em análise tenta se referir ou dar algum tipo de 
resposta. A quinta etapa é aquela em que o estilo do enunciado (que se manifesta através de escolhas lexicais, fraseológicas e sintáticas) é analisado.

Por fim, na sexta etapa, construímos discussões inéditas que buscam a convergência dos resultados anteriores de forma a revelar nosso excedente de visão como pesquisadores, ou seja, de modo a apresentar asserções e raciocínios que apenas as nossas posições como sujeitos do discurso poderiam propiciar.

\section{IV.1 O enunciado e seu contexto imediato}

O enunciado concreto, objeto de nossa análise, é o livro A cura quântica - no original, Quantum healing: exploring the frontiers of mind/body medicine - escrito por Deepak Chopra e publicado pela primeira vez pela Bantam Books em 1989. Consideramos, em nossa análise, o enunciado em sua completude, da ficha catalográfica até a última página (e não enunciados em particular como seus capítulos individuais, por exemplo) por entendermos que é exigida do leitor uma leitura integral do livro para um entendimento pleno ou, mais especificamente, para uma compreensão responsiva.

Em outras palavras, identificamos que a alternância de sujeitos do discurso só é verdadeiramente estabelecida em A cura quântica com uma leitura integral, pois a exaurabilidade do tema não se concretiza em capítulos ou seções ao longo do livro, apenas em seu fim. Outro fator importante é que o projeto de fala de Chopra estende-se por todos os capítulos e é só sintetizado no final da segunda parte do livro. Além disso, o gênero do discurso ao qual a obra pertence (que é discutido na seção IV.2) não justifica uma leitura parcial ou fragmentada, pois isso não condiz com o acabamento que seus enunciados tipicamente recebem.

Para delinear a estrutura do enunciado, destacamos que o livro é composto por uma breve introdução e por catorze capítulos organizados em duas seções principais. A introdução funciona como um simples delineamento do contexto no qual o enunciado foi escrito, algo que abordamos na seção IV.1.2, e de seu interesse especial pelo papel da cura na medicina.

Nos capítulos iniciais da primeira parte do livro, Chopra narra casos de "cura espontânea" de indivíduos que acompanhou durante sua carreira ou sobre os quais soube da ocorrência durante seus anos de estudo. Essa parte do texto se divide em capítulos em que dissertam sobre sua crença em como há uma "consciência" ou "inteligência" natural no corpo humano que é responsável por esses casos e, posteriormente, em capítulos que tratam sobre como a medicina moderna, especificamente áreas como endocrinologia e neurologia, explica processos de cura. Nos capítulos finais da primeira parte, o autor foca no entrelaçamento de todas as informações dadas sobre endocrinologia e neurologia com algumas metáforas e com suas interpretações pessoais dos fundamentos de FQ, comentando sobre quais seriam as supostas consequências filosóficas da FQ em estudos sobre o processo da cura.

No começo da segunda parte do livro, Chopra interrompe brevemente a sequência de argumentos vistos até então para narrar sua reaproximação com a cultural indiana. Nesses 
capítulos, o autor constrói paralelos entre antigas ideias presentes na filosofia indiana com frases atribuídas a indivíduos como Albert Einstein e com conceitos e termos da área de cosmologia e da FQ. Com isso, são elaboradas reflexões sobre a natureza da realidade na filosofia holística na qual Chopra se insere em uma seção do livro que evidentemente está relacionada à tese de que "Religiões orientais já teriam chegado às principais ideias da fisica moderna", algo que, segundo Pessoa Jr. (2011), é relativamente comum em argumentos de enunciados do misticismo quântico. Por fim, nos últimos capítulos da segunda parte, Chopra apresenta suas ideias sobre as origens de doenças no corpo humano, sobre como a FQ estaria supostamente associada a isso e sobre como seria possível seguir o caminho da "cura quântica" que ele propõe para estabelecer um novo tipo de abordagem médica.

Nas seções a seguir, apresentamos as análises que exploram a supracitada delimitação do enunciado.

\section{IV.1.1 O conteúdo temático}

A cura quântica é um livro que trata, acima de tudo, sobre "cura"; algo que se torna evidente logo na introdução quando "cura" é especificamente apresentada como "um dos grandes mistérios da medicina" (CHOPRA, 2013, p. 10). Temas como "medicina ayurvédica" e "física quântica" são relativamente secundários, pois o enunciado é focado fortemente em informar o leitor sobre ideias e reflexões sobre o processo da cura em um sentido amplo de "superação holística de transtornos físicos e mentais": superar o câncer, superar a AIDS, superar vícios ou maus hábitos etc.

O conceito que dá título à obra é com certeza uma parte relevante de seu conteúdo temático, especialmente nos últimos capítulos, e é definido de formas diversas durante o texto do enunciado, mas, com todas as informações contidas nele, pode ser entendido como um conjunto de três tratamentos ayurvédicos rotulados como "quânticos" porque Chopra defende que entre os componentes fundamentais da realidade e da consciência humana existe um estado de "vazio" (ou um "silêncio", em suas palavras) através do qual o corpo humano pode executar "saltos quânticos" que levariam a um estado de cura. Essa argumentação do autor pode ser entendida como a manifestação da premissa de que "A física quântica fundamentaria terapias alternativas", segundo a proposta de classificação de teses do misticismo quântico de Pessoa Jr. (2011).

Para fortalecer o conteúdo temático principal, Chopra desenvolve outros temas, como "memória", "inteligência", "física quântica" e "cosmologia". Esses conteúdos podem ser considerados como temas secundários de A cura quântica não só pelo destaque que recebem ao complementar o assunto principal, mas também porque são especialmente usados para a construção de metáforas com conceitos científicos. 


\section{IV.1.2 O autor e o contexto extraverbal}

Deepak Chopra nasceu na segunda metade da década de 1940 em Nova Déli na Índia em uma família bem abastada e com tradição de serviço militar no Exército Indiano ${ }^{6}$. Seu pai era um cardiologista de excelência e a sua educação básica ocorreu na renomada St. Columba's School. Entre 1968 e 1970, Chopra graduou-se no All India Institute of Medical Sciences. Nesse mesmo período, casou-se com sua esposa, Rita Chopra, e juntos emigraram para os EUA onde ele pode exercer sua profissão sem grandes dificuldades pela necessidade do país de recrutar médicos para substituir aqueles que estavam no esforço de guerra no Vietnã. Durante a década de 1970, Chopra consolidou sua formação e sua prática profissional nos EUA: fez residências, especializando-se em clínica médica e endocrinologia, se tornou chefe do quadro de funcionários do New England Memorial Hospital e trabalhou com atendimentos particulares em Boston (BAER, 2003; CHOPRA, 1989, 1991; CHOPRA; CHOPRA, 2013).

Ao contrário de figuras proeminentes do misticismo quântico, ou mais especificamente, de figuras a partir da "terceira estação" do misticismo quântico (PAURA, 2018), como Fritjof Capra e Fred Alan Wolf os quais eram físicos de formação que encontraram dificuldades em exercer a profissão tradicionalmente em instituições de pesquisa nas décadas de 1970 e 1980 (KAISER, 2011), Chopra esteve em espaços formais de educação, de pesquisa (clínica) e de exercício profissional altamente qualificado por bastante tempo. Um argumento evidente de que a profissão médica dificilmente passa por problemas como passou a carreira de um físico nos anos finais da Guerra Fria pode ser feito, mas esse detalhe de sua trajetória ainda pode ser considerado como algo notável.

Em paralelo ao contexto de estabilidade da profissão médica nos EUA devido ao esforço de guerra, há também, desde o fim da década de 1950, mas especialmente a partir dos anos de 1970, o que podemos descrever como uma "nova diáspora" asiática nas Américas, protagonizada por cidadãos do sul e sudeste asiático (ZONG; BATALOVA, 2016). A tomada do Tibet pela República Popular da China e outros eventos geopolíticos locais levaram à migração de muitos cidadãos asiáticos, incluindo o $14^{\circ}$ Dalai Lama, para países próximos (como a Índia) e, mais tarde, para as Américas (TU; DU, 1971). A aproximação sociocultural entre o sudeste asiático e os Estados Unidos pode também ser representado pela popularidade adquirida na época por indivíduos como o artista marcial Bruce Lee, a autoridade budista Dalai Lama e o guru indiano Maharishi Mahesh Yogi ${ }^{7}$.

A partir de 1980, a vida de Chopra passa a sofrer grandes mudanças. Com a leitura de um livro sobre meditação transcendental, ele começou a refletir mais sobre sua vida,

\footnotetext{
6 Mais especificamente, seu avô paterno e seu pai serviram no antigo Exército da Índia Britânica. Sua data de nascimento é incerta, como o próprio autor admite em um de seus livros (CHOPRA; CHOPRA, 2013) ao reconhecer que foi registrado em 1947, mas que seu nascimento provavelmente ocorreu em 1946.

${ }^{7}$ Responsável pelo desenvolvimento da meditação transcendental, uma técnica específica de meditação que usa mantras de forma silenciosa.
} 
especialmente sobre sua saúde e profissão (CHOPRA, 1989, 2013). O autor relata que consumia café exageradamente e que fumava praticamente um maço de cigarros por dia, hábitos que desenvolveu durante anos de stress, principalmente pelo trabalho como médico, e com os quais conseguiu parar por causa da meditação transcendental (BAER, 2003; CHOPRA, 1989). Ainda no início da década de 1980, em suas viagens costumeiras à Índia, houve também uma (re)descoberta de aspectos culturais de sua terra natal, especialmente da medicina ayurvédica ${ }^{8}$. A partir daí, sua aproximação com um paradigma holístico de saúde se desenvolveu rapidamente e, ao final da década de 1980, Chopra já havia se desiludido com a medicina moderna e a endocrinologia, abandonado seu cargo no New England Memorial Hospital, formado uma relação com Maharishi Mahesh Yogi, estabelecido centros e associações de medicina ayurvédica e publicado, em 1989, Quantum healing: exploring the frontiers of mind/body medicine, um de seus livros mais conhecidos (BAER, 2003; CHOPRA, 1989; CHOPRA; CHOPRA, 2013).

Uma aproximação com visões alternativas de saúde no final dos anos de 1980 não foi algo exclusivo a indivíduos como Chopra, mas foi, na realidade, algo bastante popular por todos os Estados Unidos a partir dos anos de 1970; um fenômeno que pode ser associado às políticas de austeridade fiscal que começaram a estabelecer que o sistema de saúde estadunidense seria profundamente atrelado à iniciativa privada. $\mathrm{Na}$ administração governamental de Ronald Reagan, os Estados Unidos experenciaram a implementação agressiva e restritiva de políticas econômicas, apelidadas de "Reaganomics", que dificultaram - e dificultam até hoje - o acesso de parte da população civil a serviços básicos, como educação e saúde, de forma digna, gratuita e/ou universal (CHAIT, 2008). Além disso, a administração de Reagan é reconhecida e muito criticada por ter sido absurdamente negligente com a saúde pública e especialmente irresponsável durante a pandemia de AIDS na segunda metade da década de 1980 (FRANCIS, 2012). Chopra chega a falar sobre a AIDS em A cura quântica, mas evidentemente não para tratar de políticas econômicas ou sanitaristas, mas para promover e apelar aos casos de "longa sobrevivência" devidos supostamente a "mudanças de hábitos" como exemplos de suas teses sobre uma "inteligência" natural do corpo humano (CHOPRA, 2013, p. 28, 54, 157, 294).

Entretanto, pouco depois dessa época, já na década de 1990, Chopra se desencanta novamente; dessa vez com Maharishi Mahesh Yogi e com o movimento associado à meditação transcendental e acaba por distanciar-se de ambos sem dar claras explicações, mas mantem seu foco na medicina ayurvédica e na medicina mente-corpo ${ }^{9}$. É nesse período que ele se muda para a costa oeste dos EUA, mais especificamente para a Califórnia, e que grandes polêmicas sobre seu trabalho e vida pública começam a se tornar frequentes; várias das quais chegaram a cortes de justiça (NY TIMES, 1996). Nessa época, como comentamos

\footnotetext{
8 Tradição medicinal hindu cujas práticas e técnicas que permanecem em uso ou que foram relativamente modernizadas são frequentemente consideradas como medicina alternativa.

${ }^{9}$ Forma de medicina alternativa associada a um paradigma holístico de saúde.
} 
brevemente antes, Chopra esteve envolvido com acusações de omissão de interesses financeiros por um artigo de sua coautoria publicado no Journal of the American Medical Association (JAMA, 1991; SKOLNICK, 1991). Além disso, Chopra ofereceu atendimentos particulares sem licença médica adequada do estado da Califórnia sob a explicação, feita por uma funcionária da Sharp HealthCare onde ele era o diretor executivo, de que ele não atendia seus pacientes formalmente como médico na clínica que estabeleceu (PETTUS, 1995).

\section{IV.2 O gênero do discurso}

Para demonstrar a qual tipo relativamente bem estabelecido de enunciados pertence A cura quântica, destacamos a existência de pontuais semelhanças entre a arquitetônica textual do enunciado (a estrutura composicional, escolha lexical e estilo) de Chopra e a literatura não fíccional de divulgação científica. Esse destaque, entretanto, é feito com cautela, pois o mínimo de tecnicidade que é possível encontrar em algumas passagens pode ser completamente não intencional e claramente tem diferentes níveis de organização, qualidade e profundidade. Semelhanças assim podem ser pontualmente observadas na introdução do livro e em capítulos como "O corpo possui mente própria". Entretanto, elas estão constantemente acompanhadas por ênfases em experiências pessoais e insights que apelam para a emocionalidade, por metáforas com os mais diversos graus de poder explicativo, e por um conteúdo temático de natureza polêmica e "alternativa". Como afirma Warrier (2019), essa ênfase em experiências pessoais e insights pode ser compreendida como a representação da crença de que a autoridade epistemológica máxima está exclusivamente no indivíduo, na experiência pessoal, ou seja, como a representação de um "individualismo epistemológico" em que as vozes de autoridades devem ser avaliadas e mediadas, basicamente "filtradas", pela experiência pessoal do indivíduo. Dessa forma, consideramos muito mais adequado descrever A cura quântica como sendo do gênero literário não ficcional de autoajuda.

É a partir dessas características que Chopra constrói um enunciado que mobiliza dialogicamente conceitos científicos, religiosos e psicológicos de forma a romper com o caráter estável e razoavelmente homogêneo que esses tópicos possuem em outros gêneros discursivos, resultando em, como destacamos adiante, argumentações contraditórias em seu enunciado concreto que não são capazes de realmente formar uma síntese de tudo aquilo que o autor apresenta.

Por fim, é preciso destacar que os gêneros discursivos de quaisquer livros de prosa, mesmo de não ficção, são gêneros secundários, ou seja, gêneros complexos que surgem a partir do ato de criar enunciados a partir de instrumentos culturais (BRAIT, 2005) e, consequentemente, A cura quântica surge do mesmo tipo de ato. Além disso, cabe apontar que "não ficção" é um termo que se popularizou muito no mercado literário, mas que até hoje gera dúvidas e críticas (KEEN, 2015), mas é popularmente utilizado para diferenciar produtos literários tradicionais dos produtos de desenvolvimento pessoal e autoajuda. Entretanto, atualmente, o uso da expressão se generalizou bastante e, por isso, acreditamos ser necessário 
introduzir descritores como "divulgação científica", "livro didático", “autoajuda", "biografia", entre outros para realmente estabelecer um bom entendimento do gênero do qual estamos falando.

\section{IV.3 O direcionamento e a orientação social}

Existem diversas formas de se identificar a quem o enunciado se endereça e qual é a sua orientação social. Nesta seção, iniciamos essa identificação através da análise do mercado de livros de autoajuda.

No contexto estadunidense, o público consumidor do gênero literário não ficcional de autoajuda é historicamente formado em grande parte por mulheres (aproximadamente 70\%) que vivem nas regiões costeiras do país (MARKETDATA LCC, 2015). Entretanto, Nehring e colaboradores (2016) afirmam que o fenômeno cultural da autoajuda em geral possui um caráter popular e transnacional relacionado à homogeneidade político-ideológica (neoliberal) em seu discurso que faz com que seus temas circulem facilmente pelo mundo inteiro e entre quaisquer indivíduos atraídos por desenvolvimento pessoal e bem-estar. Os autores também reafirmam as semelhanças encontradas por outras pesquisas sobre a circulação e divulgação da autoajuda nos EUA, na Grã-Bretanha, no México, em Israel, na Alemanha, nos Países Baixos, no Brasil e em diversos outros locais.

Apesar das diferenças entre o público consumidor de autoajuda da década de 1980 e o público dos anos de 2010, há um consenso sobre sua homogeneidade demográfica a qual, apesar de diversas flutuações, vem aumentando consideravelmente mais em número de indivíduos do que em diversidade entre eles ${ }^{10}$ (NEHRING et al., 2016; MARKETDATA LLC, 2015). Porém, é importante apontar que as pesquisas mais notáveis de delineamento do perfil desse público consumidor surgem a partir dos anos de 1990 e, portanto, é incerto se Chopra tinha plena consciência de todas essas variáveis. Em outras palavras, é inteiramente possível que "mulheres estadunidenses que moram em zonas costeiras" não fossem o auditório, ou público-alvo, almejado por Chopra, independentemente de o autor reconhecer ou não seu trabalho como sendo literatura não ficcional de autoajuda. Entretanto, é bastante razoável assumir que ele tivesse alguma ideia ou reconhecimento básico de a quem estava direcionando seu livro e quem realmente iria lê-lo, com ou sem as informações de pesquisas que delineavam o perfil de seu público em potencial.

Para uma verdadeira identificação do auditório e da orientação social de um enunciado, também é necessário considerar seu contexto extraverbal e endereçamentos feitos, clara ou obscuramente, no próprio texto do enunciado. Como comentado anteriormente, na década de 1980, a vida pessoal de Chopra passou por profundas mudanças, entre as quais destacamos a reaproximação com suas heranças culturais da Índia e a mudança de hábito que o fez parar de fumar, começar a praticar meditação transcendental e imergir no mundo da 10 Para informações adicionais e uma perspectiva diferente na análise das características demográficas do
público consumidor de livros de autoajuda, recomendamos o texto de Zhou (2017). 
medicina alternativa, mais especificamente da medicina ayurvédica. Essa imersão claramente criou na consciência de Chopra uma necessidade de divulgá-la e legitimá-la para um grande público. Como o próprio autor afirma: "Precisava demonstrar que aquela era uma ciência por seus próprios méritos. Como fazer isso? A resposta acabaria por surgir. O pensamento indiano tem se baseado sempre na convicção de que Satya, a verdade, triunfa por si" (CHOPRA, 2013, p. 14). Afirmamos que é altamente provável que a intenção era atingir um grande público, e não especificamente a comunidade científica, pois, apesar de querer "demonstrar que aquela era uma ciência por seus próprios méritos", Chopra claramente restringe o alcance de seu trabalho por optar publicá-lo em forma de livro sem adotar uma estratégia de divulgação focada em espaços formais de pesquisa e sem considerar os princípios de um texto rigorosamente acadêmico como, por exemplo, ao não sinalizar de forma adequada referências, bibliografias recomendadas ${ }^{11}$ ou menções a fontes primárias.

Dando outro exemplo de como a orientação social pode ser percebida pela interpretação do enunciado concreto e não apenas por seu contexto extraverbal, podemos destacar como, a partir de "Uma introdução pessoal" e do capítulo "Após o milagre", o leitor é apresentado a certos conflitos entre argumentações: na introdução, Chopra elabora uma negação do conceito de "milagre" na qual ele afirma não ver as curas espontâneas de seus pacientes do passado como milagres. Essa negação colocada na parte introdutória do livro serve para que o leitor não sinta um desconforto com a possibilidade de que o autor (que se apresenta inicialmente como um médico imerso no paradigma biomédico e científico de saúde) vá se afastar de temas e abordagens científicas. Porém, no início do capítulo seguinte lemos: "Em minha carreira médica, por várias vezes tive o privilégio de presenciar curas miraculosas" (CHOPRA, 2013, p. 19). Essa afirmação, que contradiz a primeira, funciona como um "apito de cachorro" ou "apito silencioso", para o autor se comunicar diretamente com leitores que naturalmente aceitariam de modo não conflitante, ou melhor, que costumam ignorar contradições assim, e que seriam mais facilmente convencidos pelos paralelos e pelas metáforas que omitem ou modificam conceitos e consensos científicos bem estabelecidos e que são usadas posteriormente no livro. Evidentemente, esse é um exemplo de caráter anedótico bem ao início da obra e, independentemente de ser proposital ou não, é justamente por esse caráter e por sua localização nesse enunciado que ele é capaz de exemplificar as contradições presentes na tentativa de se comunicar através de um enunciado que busca hibridizar o gênero literário não ficcional de autoajuda com o gênero literário não ficcional de divulgação científica.

11 Existem edições, especialmente as edições estadunidenses, que possuem uma breve lista de leituras recomendadas, as quais são indicadas mais como textos semelhantes do que como materiais de aprofundamento dos temas em pauta. 


\title{
IV.4 A responsividade
}

A cura quântica é um enunciado que é responsivo a inúmeros outros enunciados passados, por exemplo, de figuras como Maharishi Mahesh Yogi, Albert Einstein, Arthur Eddington, David Bohm, John S. Bell, entre outros. É responsivo, também, a enunciados do gênero do discurso científico como pesquisas clínicas sobre hipnose, meditação e cura espontânea. Entretanto, focamos nossas análises da responsividade de A cura quântica em relação aos enunciados concretos com mais relevância para o Ensino de Física: especificamente nos enunciados concretos de Arthur Eddington e Albert Einstein.

Apesar de Chopra não apresentar adequadamente as referências aos enunciados em que suas interpretações se embasam e a que enunciados elas respondem, é possível, em uma interpretação metalinguística, acionar o excedente de visão que nós, os autores dessa interpretação, possuímos para realizar as devidas análises.

Sobre as menções a Arthur Eddington em A cura quântica, por exemplo, reconhecemos que sua obra, além de seu valor didático, é reconhecida por mencionar um tipo de conteúdo "desconhecido" da "Natureza" que estaria relacionado ao "Tempo" e à "Verdade" quando discute implicações filosóficas da "Nova Teoria Quântica" para o embate entre FQ e Física Clássica na solução do problema da propagação da luz:

\begin{abstract}
Uma ação quântica pode ser o meio de nos revelar algum fato sobre a Natureza, mas, simultaneamente, um novo desconhecido é implantado no ventre do Tempo. Um acréscimo ao conhecimento é obtido às custas de um acréscimo à ignorância. É difíil esvaziar o poço da verdade com um balde furado (EDDINGTON, 2007, p. 115 , tradução nossa).
\end{abstract}

Entretanto, um foco exagerado nas reflexões metafísicas de Eddington, como Chopra faz, pode ofuscar alguns esclarecimentos que o próprio autor faz ao seu auditório no mesmo capítulo, mas antes de se aprofundar em reflexões como a que citamos anteriormente:

\footnotetext{
De vez em quando, são feitas descobertas fisicas; e novas entidades, surgindo do desconhecido, tornam-se conectadas à nossa experiência e são devidamente nomeadas. Mas deixar muitos rótulos desconexos flutuando no ainda indiferenciado desconhecido na esperança de que eles possam ser úteis mais tarde, não é nenhum sinal particular de pré-ciência e não é útil para a ciência (EDDINGTON, 2007, p. 111 , tradução nossa).
}

De qualquer forma, consideramos razoável afirmar que, com base nos trechos supracitados e em diversos outros (EDDINGTON, 2007, p. 130-135, 146-147), Chopra busca frequentemente ser responsivo às reflexões que permeiam a obra "The Nature of the Physical World", mas sem reproduzir ou mencionar os argumentos de Eddington sobre o caráter ilusório e pouco produtivo de algumas dessas ideias.

Quanto às menções a Albert Einstein como, por exemplo, a afirmação, feita entre parêntesis e sem referência bibliográfica adequada, de que "Einstein se considerava 
profundamente espiritualizado" (CHOPRA, 2013, p. 197), reconhecemos a existência de diferentes modos válidos de análise. Entretanto, ao focarmos em uma estratégia interpretativa de mediação e ceticismo, torna-se claro o quão reducionista é a interpretação de Chopra sobre a visão que Einstein tinha de si mesmo. Max Jammer (2000), por exemplo, demonstra como as complexas influências etnoculturais de uma herança judaica e de conflitantes crenças socioculturais transformaram radicalmente o pensamento de Einstein inúmeras vezes por toda a sua vida.

Ao encontro disso, quando exploramos os enunciados concretos de Einstein, encontramos opiniões mais complexas e ponderadas do que simplesmente se reconhecer como "profundamente espiritualizado"; encontramos, inclusive, afirmações praticamente contrárias como sua expressa preferência em ser reconhecido como "agnóstico" (CALAPRICE, 2011, p. 340). Se em algum momento Einstein chegou perto de um afirmação assim, foi algo que ocorreu claramente em um contexto específico e por causa de suas ideias sobre uma "religião cósmica"; uma crença metafísica sobre religiosidade que não envolve uma ideia antropomorfizada de deus, mas que se baseia em uma confiança bem fundamentada na unidade concreta e "física" do universo (EINSTEIN; SHAW, 2009). Como Einstein foi um verdadeiro Kulturträger, "um portador de cultura", é difícil delimitar a quais enunciados Chopra tenta ser responsivo, entretanto, acreditamos ter oferecido suficientes reflexões sobre as origens dessas interpretações questionáveis.

Não deve ser inequivocamente errado afirmar que a responsividade de Chopra a Eddington e Einstein é uma materialização inadequada de um argumento de apelo à autoridade. É evidente que, especialmente pela desconsideração que Chopra demonstra ter por uma devida atribuição de créditos e adequação de referências, que o apelo à autoridade só existe pela credibilidade que o autor atribui, e vê sendo atribuída, aos dois cientistas mencionados. Chopra busca mobilizar tal credibilidade para fortalecer os argumentos de seu enunciado, ignorando o fato de que tanto Eddington quanto Einstein não são autoridades nos campos da medicina, da espiritualidade e muito menos da medicina alternativa e que ambos tiveram contribuições fundamentais, mas consideravelmente específicas aos fundamentos de FQ.

\section{IV.5 O estilo}

Em uma interpretação metalinguística, a análise do estilo de um enunciado concreto exige a identificação de escolhas lexicais, ou seja, dos conjuntos de palavras usadas e suas funções. Para tanto, ilustramos as escolhas lexicais mais frequentes de Chopra em $A$ cura quântica através do Quadro 1, elaborado através de mineração de texto, para apresentar uma seleção de palavras utilizadas no livro por mais de 45 vezes. 
Quadro 1 - Lista de palavras mais frequentes em A cura quântica ordenadas decrescentemente.

\begin{tabular}{|c|c|c|c|c|c|c|c|}
\hline palavra & frequência & palavra & frequência & palavra & frequência & palavra & frequência \\
\hline corpo & 380 & celula & 105 & ponto & 70 & capacidade & 55 \\
\hline ser & 349 & pacientes & 104 & normal & 69 & quimicas & 55 \\
\hline pode & 290 & pessoas & 100 & ayurveda & 68 & fisica & 53 \\
\hline mente & 246 & sistema & 100 & verdade & 68 & ideia & 53 \\
\hline cancer & 199 & parte & 95 & dia & 67 & interior & 53 \\
\hline tempo & 195 & caso & 94 & homem & 65 & memoria & 53 \\
\hline cerebro & 171 & fato & 91 & medicos & 64 & momento & 53 \\
\hline voce & 166 & natureza & 90 & percepcao & 64 & simples & 53 \\
\hline dna & 164 & forma & 89 & coracao & 63 & ciencia & 52 \\
\hline vida & 162 & campo & 86 & moleculas & 63 & lugar & 51 \\
\hline celulas & 161 & modo & 86 & organismo & 63 & aventuranca & 49 \\
\hline anos & 149 & grande & 84 & rishis & 63 & energia & 49 \\
\hline inteligencia & 146 & materia & 82 & cento & 62 & causa & 48 \\
\hline doenca & 140 & tratamento & 82 & pessoa & 60 & meditacao & 48 \\
\hline realidade & 132 & espaco & 77 & dor & 59 & quimica & 48 \\
\hline paciente & 131 & nivel & 76 & exemplo & 58 & humano & 46 \\
\hline cura & 124 & consciencia & 74 & sangue & 58 & imunologico & 46 \\
\hline medico & 123 & experiencia & 74 & substancias & 58 & vazio & 46 \\
\hline quantum & 122 & processo & 74 & coisa & 57 & maior & 45 \\
\hline mundo & 119 & pensamento & 72 & meio & 56 & pensamentos & 45 \\
\hline medicina & 118 & luz & 70 & pensar & 56 & sinais & 45 \\
\hline
\end{tabular}

É igualmente importante identificar as escolhas semânticas que acompanham as escolhas lexicais. Por exemplo, o termo "nível" surge com muita frequência porque está vinculado ao conceito de "nível quântico", assim como o termo "corpo" surge frequentemente não apenas porque o livro trata sobre "medicina mente-corpo", mas também porque um de seus conceitos centrais é o "corpo mecânico quântico". "Inteligência" e "memória" são palavras que surgem com considerável frequência especialmente porque Chopra atribui diferentes significados a elas a partir de sua visão de mundo relacionada à medicina alternativa. Essas características não são apenas descrições da função que tais palavras exercem, mas também dos novos significados que mobilizam (no caso, significados metafóricos em relação a conceitos científicos) e, portanto, configuram-se como exemplos de escolhas semânticas.

Para fortalecer nosso argumento de que os fundamentos de FQ não devem ser considerados como o conteúdo temático principal do livro, destacamos que, ao construir o Quadro 1, as palavras "quântica", "quânticas", "quântico" e "quânticos" foram substituídas por "quantum" e, mesmo com essa estratégia, obtemos uma frequência resultante menor do que a de termos como "tempo" ou "DNA". "Cura", elemento que identificamos como o tema principal, aparece poucas vezes mais que "quantum", porém termos análogos ("tratamento", "medicina") e palavras fortemente relacionadas à mensagem de superação de transtornos 
físicos e mentais ("doença”, “câncer”) surgem com muita frequência e demonstram a acurácia na identificação do tema do enunciado.

Algumas das palavras de maior frequência funcionam basicamente como um atalho no ato de comunicação entre o locutor e seu auditório. A palavra "luz", por exemplo, não surge com tanta frequência apenas porque Chopra discute sua natureza e menciona a dualidade onda-partícula: seu uso repetitivo é devido a uma popular associação, não completamente descabida, entre "luz" e a palavra "energia" que, por sua vez, é frequentemente interpretada não através das diferentes conceitualizações científicas, mas de concepções holísticas e alternativas (GUERRIERO; STERN, 2017).

Quanto às escolhas fraseológicas e à estrutura composicional do enunciado, destacamos que, em "Uma introdução pessoal", há a apresentação consideravelmente desordenada de diversos dos elementos estilísticos iniciais de enunciados do gênero literário não ficcional. $O$ enunciado apresenta frases de delineamento do tema, descrições de experiências pessoais, estabelecimento das premissas do trabalho, menções a experiências profissionais, caracterização da filosofia que fundamenta a maior parte da obra (a medicina ayurvédica) e a composição de (algo semelhante a) "problemas de pesquisa" ou "questões norteadoras".

A primeira parte do livro, "A fisiologia oculta", é onde todo o estilo é focado em hibridizar, ou melhor, intercalar frases que, por um lado, descrevem evidências factuais sobre "curas espontâneas" com frases que, por outro lado, descrevem experiências relativamente pessoais do autor e de seus pacientes através do enfoque nos conceitos de "memória" e "inteligência". Chopra aponta ao leitor a conclusão de que esses casos de curas não podem ser entendidos como eventualidades, como, por exemplo, quando afirma que:

Quando uma célula de sangue chega à borda de um corte e começa a formar um coágulo, não viajou até ali ao acaso. Sabe realmente aonde quer ir e o que fazer quando chegar, com a mesma certeza de um especialista - com mais até, de fato, já que age de forma completamente espontânea e não procura adivinhar (CHOPRA, 2013, p. 54).

Há um padrão que se repete no estilo do enunciado, não apenas durante a primeira seção do livro, mas especialmente nas conclusões dos capítulos: quanto mais afirmações extraordinárias são feitas, mais metáforas são usadas, enquanto menos evidências científicas ou minimamente factuais são apresentadas. Evidências e fatos são mais frequentes nos inícios dos capítulos e geralmente não correspondem adequadamente ao nível de explicação exigido pelas afirmações de Chopra. O capítulo 2, "O corpo possui mente própria" (CHOPRA, 2013, p. 31-50), representa adequadamente esse padrão.

$\mathrm{Na}$ segunda e última parte do livro, "Corpo de bem-aventurança", fica definitivamente estabelecido que, na visão de mundo de Chopra, curas espontâneas ocorrem porque o corpo humano é essencialmente sua consciência (que é sempre atrelada aos conceitos de "memória" e "inteligência" supracitados). A consciência, por sua vez, é 
essencialmente "quântica" já que, para o autor, nós, humanos, "[s]omos como uma luz que irradia não fótons, mas consciência" (CHOPRA, 2013, p. 250). Isto é, o ser humano, ou mais especificamente o "corpo mecânico quântico", supostamente possui algo que atua como sua "partícula mediadora", a consciência, que, assim como o fóton, tem uma natureza misteriosa e dual que desafia noções de causa e efeito; algo que o autor já havia tangencialmente estabelecido na primeira parte do enunciado ao afirmar que "[n] ão existe uma linha reta de ligação entre um pensamento imaterial e um objeto material, mesmo que seja minúsculo como uma molécula-peptídio" (CHOPRA, 2013, p. 116).

\section{IV.6 Discussão}

É preciso reforçar que, talvez não surpreendentemente, a Física Quântica não é o tema principal do livro analisado e muito menos parte fundamental do conceito de "cura quântica". Isto é, não há uma relação concreta entre a tese principal do livro e os formalismos matemáticos da FQ ou com as regras que pesquisadores usam para criar correspondências entre fenômenos empíricos e equações de teorias físicas. Quando Chopra faz uma metáfora que busca justificar ou explicar o que há de "quântico" em sua ideia de cura, não há menções a algo como, por exemplo, os axiomas ou a elegância matemática da notação bra-ket de Paul Dirac. Não há referências às regras de correspondência da FQ, excetuando-se menções muito pontuais ao teorema de Bell. Não há, também, propostas ou avaliação de possíveis arranjos experimentais para testar suas ideias porque, como o próprio autor afirma:

Como a física quântica lida com aceleradores de altíssima velocidade, você pode pensar que a cura quântica emprega radioisótopos ou raios X. Mas o significado é o oposto. A cura quântica afasta-se dos métodos da alta tecnologia e penetra nos meandros mais profundos do sistema mente-corpo (CHOPRA, 2013, p. 29).

Quando o enunciado de Chopra traz menções e reflexões sobre fundamentos de FQ, são construídos argumentos que servem como uma forma de tornar o conceito de "quantum" em uma simples commodity (isto é, em um simples produto do trabalho intelectual que pode ser comercializado irrestritamente) que agrega valor às mercadorias e aos serviços que o autor oferece (livros, palestras, mentorias, produtos estéticos) através da Chopra Foundation e de seu site pessoal. A esse processo de inserção do conceito de quantum e de outros aspectos dos fundamentos de FQ em uma lógica mercadológica, o trabalho de Burwell (2018) atribui a alcunha de comodificação do quantum.

Se há qualquer tipo de relação genuína entre o discurso de Chopra e a FQ, ela está no âmbito de outro elemento importante de qualquer teoria científica: as interpretações; neste caso, de fundamentos de FQ. Isto é, se pudermos realmente considerar a existência de uma relação entre cura quântica e FQ, ela existe apenas no que tange às teses que se agregam a formalismos abstratos e a regras de correspondência; elementos que favorecem um maior poder explicativo para as teorias. Mais especificamente, a relação poderia estar nas 
consequências ontológicas, sobre a natureza da realidade, e, em menor grau, nas consequências epistemológicas de algumas interpretações da FQ especialmente discutidas por indivíduos como Arthur Eddington e David Bohm os quais Chopra faz questão de citar, sem nunca indicar a fonte primária da qual extraiu os enunciados desses cientistas, revelando um projeto de fala que busca persuadir através do apelo à autoridade.

Apesar disso, consideramos muito mais preciso interpretar A cura quântica como uma teoria alternativa, isto é, como um corpo de ideias com grande possibilidade de se distanciar completamente da teoria científica original à qual faz referência. A categoria de teorias alternativas que aqui usamos pode ser entendida como quaisquer conjuntos de formalismos abstratos, regras de correspondência ou interpretações que preveem novos resultados e dados empíricos (no caso de Chopra, há suas previsões sobre como a mente influencia o estado de saúde do corpo humano através de sua suposta essência quântica) ou que explicam tais resultados e previsões mobilizando conceitos com significados diferentes em relação a suas origens científicas. Muitas vezes, as teorias alternativas estão relacionadas a interpretações "modificantes" de conceitos científicos porque dependem de alterações ou omissões dos componentes da teoria original. Ademais, é possível interpretar A cura quântica não apenas uma teoria alternativa, mas como um corpo de ideias com um potencial perigoso de desinformação. Por exemplo, ao transformar termos populares entre a comunidade científica como "escala de Planck", ou "comprimento de Planck", em "zona quântica" ou "nível quântico", Chopra ignora completamente que o sistema de unidades de Planck, ao qual os primeiros termos citados são associados, possuem significados consideravelmente específicos, especialmente relacionadas a quais tipos de fenômenos físicos podem ser majoritariamente observados a partir de determinados intervalos de tempo, comprimentos ou quantidades de energia e também relacionados à escala na qual as formas de se descrever fenômenos subatômicos que conhecemos atualmente se tornam inadequadas ou incompletas. Ao ignorar isso, o autor reduz esses conceitos e os confunde com alguns termos que descreveriam escalas de comprimento e energia em que fenômenos quânticos acontecem.

Mais especificamente, podemos apontar como Chopra utiliza os termos "estado de vigília", "estado de consciência", "estado de percepção subjetiva" e "estado de ânimo positivo" ou "negativo" como metáforas aos conceitos de "estado de energia" e "campo unificado" (CHOPRA, 2013, p. 207). As propriedades relacionadas aos conceitos de "inteligência" e "memória" as quais o autor enxerga no corpo humano se manifestam nesses "estados" e também no "nível quântico". A partir dessas ideias, o autor procura estabelecer a necessidade de reconstruir o senso comum sobre o que é "corpo", e o termo que o autor considera adequado para isso é "corpo mecânico quântico".

$\mathrm{O}$ "corpo mecânico quântico" pouco tem a ver concretamente com FQ e está muito mais atrelado à interpretação de Chopra sobre o estado-da-arte do conhecimento da medicina sobre neuropeptídios nos anos de 1980. Explicando melhor: Chopra acredita que a natureza dual do fenômeno que transforma pensamentos em reações biofísicas (que, portanto, se 
refletem em atos corporais) e vice-versa é exatamente a mesma natureza que a comunidade científica descreve ao tratar da dualidade onda-partícula. E quando dizemos "exatamente", não estamos exagerando na descrição do argumento do autor:

O neuropeptídio não é um pensamento, mas move-se como ele e serve como ponto de transformação. O quantum faz exatamente a mesma coisa, só que o corpo estudado nessa questão é o universo, ou a natureza como um todo (CHOPRA, 2013, p. 114, grifo nosso).

$\mathrm{O}$ argumento que Chopra apresenta na citação pode ser parcialmente entendido como resultado de um tipo de raciocínio indutivo falho na qual "se x executa $\mathrm{z}$, e se y executa $\mathrm{z}$, então x é exatamente da mesma natureza que y" e é algo essencial ao modo como ele constrói suas metáforas e referências à $\mathrm{FQ}$. Destacamos isso porque defendemos que é por meio do entendimento de como o autor constrói seus argumentos e quando cita os fundamentos de FQ que podemos ver o que há de realmente diferente entre os conhecimentos científicos e os conhecimentos sobre os quais Chopra se enuncia.

Apesar de estar mais próxima do conceito de "neuropeptídio" do que de "quantum", a ideia de "corpo mecânico quântico" também pode ser entendida como uma defesa de teses, segundo a proposta de Pessoa Jr. (2011), como "A consciência é um fenômeno essencialmente quântico" e "No dualismo entre alma e corpo, a interação entre os dois se dá por processos quânticos", mas explicitando que, ao invés de "alma", Chopra prefere focar nos conceitos de "consciência", "memória" e "inteligência".

Como tentamos demonstrar na presente seção, é importante compreender como o conteúdo de A cura quântica torna esse enunciado em algo completamente diferente de discussões filosóficas formais sobre fundamentos de FQ. Entretanto, como tentamos demonstrar em seções anteriores, também é fundamental explicitar, para estudantes e até mesmo para docentes que não estão familiarizados com a obra, quais são as condições históricas e materiais que deram origem ao livro e o sustentaram como um enunciado de longeva influência no debate público.

\section{Considerações finais}

Neste trabalho, buscamos construir uma análise metalinguística sobre como Deepak Chopra, com base em sua formação profissional como médico e sua formação cultural como divulgador da medicina mente-corpo durante um zeitgeist significativamente favorável às suas ideias (como abordado na seção IV.1.2), construiu um material linguístico concreto, A cura quântica, focado na ideia de "cura" como "superação holística de transtornos físicos ou mentais" (seção IV.1.1) que infundiu profundamente o imaginário popular. Buscamos, também, demonstrar como Chopra contribuiu para as diversas mudanças no modo como as pessoas mobilizam conceitos relacionados à Física Quântica em atos de comunicação cotidiana na internet (seção II). Sua obra não ficcional de autoajuda (seção IV.2) se direciona 
a um público consideravelmente específico, mas possui uma abordagem popular e "transnacional" (seção IV.3) que faz referências arbitrárias a concepções de indivíduos como Arthur Eddington, Albert Einstein e Maharishi Mahesh Yogi (seção IV.4). Tudo isso feito a partir de um estilo (seção IV.5) no qual conceitos como "inteligência", "memória" e "corpo" são redefinidos e excessivamente usados a partir de uma síntese inconsistente entre visões de mundo místicas e alternativas (Ayurveda e medicina mente-corpo) e uma visão de mundo científica (Física Moderna e Contemporânea); síntese na qual o autor não procura evitar metáforas incoerentes ou graves contradições, deixando-as frequentemente em destaque.

Sua interpretação sobre os fundamentos de FQ consiste basicamente em argumentar sobre a existência de algo essencialmente "quântico", em um sentido bastante superficial e tangencial à área da Física, no corpo humano, em seu funcionamento biofísico e em algum suposto componente "transcendental" ou puramente "imaterial" presente em todas as pessoas. Essas concepções são tão reconhecidas e criticadas que Osvaldo Pessoa Jr. começa seu clássico artigo sobre o misticismo quântico com uma clara tentativa de "desmitificar" essa visão, abordando-a através de uma analogia que pode funcionar como um eficiente contraponto:

Para se explicar o funcionamento de uma bicicleta, por exemplo, não é necessário usar a Teoria Quântica, mesmo que se possa argumentar que, em princípio, uma descrição quântica da bicicleta seja possível. Assim, podemos dizer que a física quântica não é "necessária", não é "essencial", para se explicar uma bicicleta, no sentido de que a física clássica fornece uma explicação suficientemente boa para este meio de locomoção (PESSOA JR., 2011, p. 281).

Ao invés de reações de perplexidade ao ouvirmos de nossos estudantes ou colegas qualquer menção a produtos "quânticos", podemos nos utilizar dessa analogia. Com ela, podemos contribuir com o entendimento de que nenhum produto ou serviço como um colchão ou tratamento de saúde, por exemplo, que seja de boa proveniência (vindo diretamente de instituições oficiais de pesquisa e desenvolvimento, por exemplo) precisaria ser necessariamente explicado, fabricado ou completamente reformulado pela Física Quântica.

A área de Ensino há anos discute a necessidade de se estabelecer fundamentos epistemológicos e abordar mais Física Moderna e Contemporânea na educação básica e em diferentes etapas do ensino superior. Entretanto, a FMC que está presente nos livros didáticos ou em metodologias tradicionais de ensino dificilmente proporciona as devidas condições para que estudantes se posicionem sobre temas como o que abordamos no presente trabalho. Portanto, reforçamos a necessidade de um ensino de FMC que esteja a serviço do entendimento de questões socioculturais, pois é altamente provável que estudantes se deparem com esses temas, tanto durante suas trajetórias educacionais quanto depois delas e, como especialistas em Educação em Ciências, somos consideravelmente responsáveis pelas formas com as quais livros como A cura quântica, e especialmente as ideias e o fenômeno cultural 
que ele representa, serão compreendidos e assimilados já que é justamente ao tipo de conhecimento que nós ensinamos que essa obra tenta se relacionar.

Defendemos também que a área de Ensino deve contribuir não só para o conhecimento técnico, mas também para o desenvolvimento de uma cultura mais ampla que propicie que discentes e docentes compreendam como conceitos e teorias são ressignificados em diferentes contextos e a inclusão de tópicos e abordagens relacionadas à Natureza da Ciência e História e Filosofia das Ciências serve justamente a isso. Esses tópicos e abordagens frequentemente exigem discussões sobre o problema da demarcação (diferenciar o que é conhecimento científico ou válido daquilo que não é). No entanto, para proporcionar uma formação educacional e científica consistente com os fundamentos e consensos epistemológicos contemporâneos é preciso tornar evidente para estudantes não só o conteúdo temático do que não consideramos científico, mas também suas dimensões socioculturais. No caso de $A$ cura quântica, que tenta tão claramente se aproximar dos fundamentos de FQ e de sua legitimidade, mas que indiscutivelmente não se configura como fruto de um trabalho científico, temos um enunciado consideravelmente adequado para essas discussões. É por isso que, através de uma interpretação metalinguística, buscamos destacar não só o que a obra diz, mas como diz, a quem responde e para quem diz. É assim que defendemos que um conjunto de ideias tão polêmico como A cura quântica de Deepak Chopra pode ser abordado por docentes, mostrando não apenas o que é diferente, mas de onde vem a diferença, qual é a sua estrutura e estilo e como circula na sociedade.

Portanto, como alternativa ou complementação, o que podemos fazer especificamente no campo dos Estudos da Ciência e da Educação em Ciências é continuar investindo em reflexões sobre as limitações da percepção humana e nossas experiências imediatas, regidas pela Física Clássica, e sobre as suas influências no modo como nos comunicamos à luz do desenvolvimento conceitual e filosófico da Física Quântica, assim como fizeram Werner Heisenberg (1995, 1996), Erwin Schrödinger (1997), Niels Bohr (1995), Fritjof Capra (1989) e muitos outros através de diferentes abordagens (BURWELL, 2018; FREIRE JR., 2015; FREIRE JR.; PESSOA JR.; BROMBERG, 2011), buscando vigorosamente expandir o alcance sociocultural dessas reflexões. Podemos até mesmo ir além, reconhecendo a necessidade de uma moldura filosófica capaz de abarcar nossos modelos e representações, que existem em uma linguagem baseada na Física Clássica, assim como nossos conhecimentos sobre Física Quântica e outros conhecimentos das ciências modernas (CAPRA, 1989; SANTOS, 2008); uma moldura filosófica que não nega ou omite o desenvolvimento conceitual, filosófico e sociocultural das mais diversas áreas do conhecimento e que seja capaz de analisar materiais linguísticos concretos, mesmo de conhecimentos alternativos, de um modo ético, fenomenológico, histórico e sociológico constantemente em desenvolvimento. Esperamos ter deixado evidente a utilidade dessa alternativa ao apresentarmos discussões que facilitam não apenas a empatia com indivíduos 
que acabam conhecendo a Física Quântica de modo tangencial e superficial, mas que também facilitam a superação pedagógica dessas compreensões limitadas.

\section{Referências bibliográficas}

ALMEIDA, Á. Assim pensa Chopra. IstoÉ, jun. 1999. Disponível em: $<$ https://istoe.com.br/31783_ASSIM+PENSA+CHOPRA/>. Acesso em: 31 ago. 2020.

BAER, H. A. The Work of Andrew Weil and Deepak Chopra: Two Holistic Health/New Age Gurus: A Critique of the Holistic Health/New Age Movements. Medical Anthropology Quarterly, v. 17, n. 2, p. 233-250, 2003.

BAKHTIN, M. Problemas da poética de Dostoiévski. Rio de Janeiro: Forense Universitária, 2002.

BAKHTIN, M. Para uma filosofia do Ato Responsável. São Carlos: Pedro \& João Editores, 2010.

BAKHTIN, M. Os gêneros do discurso. In: Estética da criação verbal. 6. ed. São Paulo: WMF Martins Fontes, 2011. p. 261-306.

BOHR, N. Física atômica e conhecimento humano: ensaios 1932-1957. 1. ed. Rio de Janeiro: Contraponto, 1995.

BRAIT, B. (Ed.). Bakhtin: conceitos-chave. 2. ed. São Paulo: Contexto, 2005.

BURWELL, J. Quantum language and the migration of scientific concepts. Cambridge: The MIT Press, 2018.

CALAPRICE, A. (Ed.). The ultimate quotable Einstein. Princeton: Princeton University Press, 2011.

CAPRA, F. O tao da física: uma exploração dos paralelos entre a física moderna e o misticismo oriental. 1. ed. Lisboa: Editorial Presença, 1989.

CHAIT, J. The big con: crackpot economics and the fleecing of America. Boston: Mariner Books, 2008.

CHOPRA, D. O retorno do rishi: a jornada de um médico indiano em busca da felicidade interior e da cura integral. 2. ed. São Paulo: Best Seller, 1989. 
CHOPRA, D. Return of the Rishi: A Doctor's Story of Spiritual Transformation and Ayurvedic Healing. Boston: Houghton Mifflin Harcourt, 1991.

CHOPRA, D. Ageless body, timeless mind: the quantum alternative to growing old. 1. ed. New York: Harmony Books, 1993.

CHOPRA, D. A cura quântica [livro eletrônico]. 1. ed. Rio de Janeiro: Best Seller, 2013.

CHOPRA, D.; CHOPRA, S. Brotherhood: Dharma, Destiny, and the American Dream. Boston: New Harvest/Houghton Mifflin Harcourt, 2013.

CUESTA-BELTRÁN, Y. J. Estado del arte: tendencias en la enseñanza de la física cuántica entre 1986 y 2016. Tecné, Episteme y Didaxis: TED, n. 44, p. 146-166, 2018.

DOERING-MANTEUFFEL, S. Survival of occult practices and ideas in modern common sense. Public Understanding of Science, v. 20, n. 3, p. 292-302, 2011.

EDDINGTON, A. S. The Nature of the Physical World. Cambridge: Cambridge University Press, 2007.

EINSTEIN, A.; SHAW, G. B. Einstein on Cosmic Religion and Other Opinions and Aphorisms. New York: Dover Publications, 2009.

FRANCIS, D. P. Deadly AIDS policy failure by the highest levels of the US government: A personal look back 30 years later for lessons to respond better to future epidemics. Journal of Public Health Policy, v. 33, n. 3, p. 290-300, 2012.

FREIRE JR., O. The Quantum Dissidents: Rebuilding the Foundations of Quantum Mechanics (1950-1990). Berlin/Heidelberg: Springer-Verlag Berlin Heidelberg, 2015.

FREIRE JR., O.; PESSOA JR., O.; BROMBERG, J. L. (Eds.). Teoria quântica: estudos históricos e implicações culturais. São Paulo: Livraria da Física, 2011.

GRECA, I. M.; FREIRE, O. Meeting the Challenge: Quantum Physics in Introductory Physics Courses. In: MATTHEWS, M. R. (Ed.). International Handbook of Research in History, Philosophy and Science Teaching. Dordrecht: Springer Netherlands, 2014. p. 183209. 
GUERRIERO, S.; STERN, F. L. The new age Concepts of Energy: the case of the Brazillian Naturology. Caminhos, v. 15, n. 1, p. 4, 2017.

HEISENBERG, W. Física e filosofia. 3. ed. Brasília: Editora Universidade de Brasília, 1995. HEISENBERG, W. A parte e o todo: encontros e conversas sobre física, filosofia, religião e política. 1. ed. Rio de Janeiro: Contraponto, 1996.

HILGER, T. R.; MOREIRA, M. A. A study of social representations of quantum physics held by high school students through numerical and written word association tests. Revista Electrónica de Investigación en Educación en Ciencias, v. 8, n. 1, p. 52-61, 2012.

HILGER, T. R.; MOREIRA, M. A.; DA SILVEIRA, F. L. Estudo de Representações Sociais sobre Física Quântica. Revista Brasileira de Ensino de Ciência e Tecnologia, v. 2, n. 2, p. $1-16,2009$.

INDIATODAY.IN. India Today Conclave 2015: Darwin was wrong, says Deepak Chopra. India Today, 2015.

JAMA. Financial Disclosure. JAMA: The Journal of the American Medical Association, v. 266, n. 6, p. 798, 1991.

JAMMER, M. Einstein e a religião: física e teologia. Rio de Janeiro: Contraponto, 2000.

KAISER, D. How the Hippies Saved Physics: Science, Counterculture, and the Quantum Revival. New York: W. W. Norton Company, 2011.

KEEN, S. Nonfiction and Fiction in Disguise. In: KEEN, S. (Ed.) Narrative Form. London: Palgrave Macmillan UK, 2015. p. 126-139.

LANG, E. Guru nos EUA se orienta pela “verdade interior”. Folha de S. Paulo, 5 out. 2000.

LIMA, N. W. et al. A Teoria do Enunciado Concreto e a Interpretação Metalinguística: bases filosóficas, reflexões metodológicas e aplicações para os Estudos das Ciências e para a Pesquisa em Educação em Ciências. Investigações em Ensino de Ciências, v. 24, n. 3, p. 258, 2019.

MACHADO, I. Gêneros discursivos. In: BRAIT, B. (Ed.). Bakhtin: conceitos-chave. São Paulo: Contexto, 2005. p. 151-166. 
MARKETDATA LCC. The U.S. Market for Self-improvement Products \& Services. Marketdata LLC, 2015. 390 p.

MEDVIÉDEV, P. N. O método formal nos estudos literários: introdução crítica a uma poética sociológica. São Paulo: Contexto, 2012.

MOURA, M. D.; SANTOS, R. P. Detectando misticismo quântico em livros publicados no Brasil com Ciência de Dados. Caderno Brasileiro de Ensino de Física, v. 34, n. 3, p. 725 744, 2017.

NEHRING, D. et al. Transnational Popular Psychology and the Global Self-Help Industry. London: Palgrave Macmillan UK, 2016.

NY TIMES. Deepak's Days in Court. The New York Times, p. 12, 18 ago. 1996.

OFFIT, P. A. Do You Believe in Magic? The Sense and Nonsense of Alternative Medicine. 1. ed. New York: HarperCollins, 2013.

PAURA, R. Le quattro stagioni del misticismo quantistico. Scienza\&Filosofia, n. 20, 2018.

PEREIRA, A.; OSTERMANN, F. Sobre o ensino de física moderna e contemporânea: uma revisão da produção acadêmica recente. Investigações em Ensino de Ciências, v. 14, n. VI, p. 393-420, 2009.

PESSOA JR., O. O fenômeno cultural do misticismo quântico. In: FREIRE JR., O.; PESSOA JR., O.; BROMBERG, J. L. (Eds.) Teoria quântica: estudos históricos e implicações culturais. Campina Grande: Livraria da Física, 2011. p. 281-302.

PETTUS, E. The Lord of Immortality. New York Magazine, p. 28-31, 95, 1995.

PIGOZZO, D.; LIMA, N. W.; NASCIMENTO, M. M. A filosofia sistêmica de Fritjof Capra: Um olhar ecológico para a Física e para o Ensino de Física. Caderno Brasileiro de Ensino de Física, v. 36, n. 3, p. 704-734, 2019.

PLAIT, P. Deepak Chopra: redefining “wrong”. Discover, sep./out. 2009.

R CORE TEAM. R: A language and environment for statistical computing. R Foundation for Statistical Computing, Vienna, 2015. Disponível em: <https://www.r-project.org/>. Acesso em: 31 ago. 2020. 
SAITO, M. T. A gênese e o desenvolvimento da relação entre Física Quântica e misticismo e suas contribuições para o Ensino de Ciências. 2019. Tese (Doutorado em Ensino de Ciências) - Universidade de São Paulo, São Paulo.

SANTOS, B. de S. Um discurso sobre as ciências. 5. ed. São Paulo: Cortez, 2008.

SCHRÖDINGER, E. O que é vida? O aspecto físico da célula viva seguido de Mente e matéria e Fragmentos autobiográficos. 1. ed. São Paulo: Editora da UNESP, 1997.

SILGE, J.; ROBINSON, D. Text Mining with R: A Tidy Approach. O'Reilly Media, 2017.

SKOLNICK, A. A. Maharishi Ayur-Veda: Guru's Marketing Scheme Promises the World Eternal "Perfect Health". JAMA: The Journal of the American Medical Association, v. 266, n. 13, p. 1741, 1991.

SOUZA, G. T. Introdução à Teoria do Enunciado Concreto do círculo Bakhtin/Volochinov/Medvedev. 2. ed. São Paulo: Humanitas/FFLCH/USP, 2002.

TU, H.; DU, H. A study of the treaties and agreements relating to Tibet: a documentary history of international relations of Tibet. Taichung: Tunghai University, 1971.

VENEU, A.; FERRAZ, G.; REZENDE, F. Análise de discursos no Ensino de Ciências: considerações teóricas, implicações epistemológicas e metodológicas. Ensaio Pesquisa em Educação em Ciências, Belo Horizonte, v. 17, n. 1, p. 126-149, 2015.

VOLÓCHINOV, V. La structure de l'enoncé. In: TODOROV, T. (Ed.). Mikhaïl Bakhtine: le principe dialogique. Paris: Seuil, 1981. p. 278-316.

VOLÓCHINOV, V. Marxismo e filosofia da linguagem: problemas fundamentais do método sociológico na ciência da linguagem. São Paulo: Editora 34, 2018.

WARRIER, M. Āyurveda and Mind-Body Healing: Legitimizing Strategies in the Autobiographical Writing of Deepak Chopra. International Journal of Hindu Studies, v. 23, n. 2, p. 123-145, 2019.

WHEEN, F. How Mumbo-Jumbo Conquered the World: A short history of modern delusions. London: HarperCollins, 2004. 
ZHOU, Y. Goodreads data show that women reading self-help books are getting advice from men. Quartz, 2017.

ZONG, J.; BATALOVA, J. Asian Immigrants in the United States. Migration Information Source, 2016. Disponível em: <https:/www.migrationpolicy.org/article/asian-immigrantsunited-states $>$. Acesso em: 31 ago. 2020. 